\title{
A MUSICALIDADE COMO INSTRUMENTO EDUCACIONAL: UMA EXPERIÊNCIA NO ENSINO MÉDIO
}

\author{
Matheus Dall'Orto Tavares ${ }^{1}$ \\ Erica Alves Pereira ${ }^{2}$ \\ Keminy Ribett Bautz ${ }^{3}$ \\ Elias Terra Werner ${ }^{4}$ \\ Aristhotelis Tadeu Tiradentes ${ }^{5}$
}

Resumo - Com a precarização do ensino imposta ao país, principalmente no que concerne a financiamentos do mesmo, os docentes encontram-se em posições delicadas sendo-Ihes impostas extensas jornadas de trabalho em diferentes instituições para a manutenção do estilo de vida desejado. Pelo fato da exaustividade da rotina docente, o tempo, tanto de planejamento quanto de ministração das aulas fica escasso devido ao conteúdo a ser aprendido ser muito vasto. Uma alternativa que pode diminuir o estresse do educador e chamar a atenção dos educandos, além de estimulá-los a aprender pode ser a utilização da musicalidade inerente ao indivíduo, por meio da confecção de paródias, viabilizando aproximar os educandos dos temas abordados e incentivar o uso da criatividade. Ao fim do trabalho foi possível observar que, ao estimular o raciocínio dos educandos e valorizar sua produção e reformulação dos conceitos compreendidos pelos mesmos, houve uma aprendizagem significativa.

Palavras-chave: Ensino; Lúdico; Paródia.

\footnotetext{
${ }^{1}$ Centro de Ciências Exatas, Naturais e da Saúde/Departamento de Biologia Universidade Federal do Espírito Santo, Brasil. E-mail: matheus.biologia.ufes@gmail.com.

2 Centro de Ciências Exatas, Naturais e da Saúde/Departamento de Biologia Universidade Federal do Espírito Santo, Brasil. E-mail: erica-alves1@hotmail.com.

${ }^{3}$ Centro de Ciências Exatas, Naturais e da Saúde/Departamento de Biologia Universidade Federal do Espírito Santo, Brasil. E-mail: keminy.bautz@gmail.com.

4 Centro de Ciências Exatas, Naturais e da Saúde/Departamento de Biologia Universidade Federal do Espírito Santo, Brasil. E-mail: eliaswerner12@gmail.com.

5 Escola Estadual de Ensino Fundamental e Médio "Professor Pedro Simão", Brasil. E-mail: tothyriradentes@gmail.com.
} 